\title{
Causes of soil acidification
}

W. de Vries and A. Breeuwsma (Soil Survey Institute, Marijkeweg 11, 6709 PE Wageningen, Netherlands)

Accepted: 7 June 1984

Abstract. Soil acidification results from natural causes, land use and acid rain. Ways of identifying and quantifying the different natural and anthropogenic sources of protons are indicated.

Key-words: natural acidification, land use, acid rain, element cycle, natural ecosystem.

Introduction. Soil acidification is known to be effected by natural processes, land use and acid rain. To quantify the relative importance of these proton sources in soil acidification (Breeuwsma \& de Vries, 1984) requires knowledge of the pertinent acid-producing and consuming processes and of the natural cycling of elements. Therefore, an overview of the relation between soil acidification and element cycling is presented.

Natural soil acidification. Soil acidification results from the uncoupling of the element cycles in an ecosystem (Ulrich, 1983). In a natural ecosystem, the cycles of all major elements (except carbon) are generally closed (uptake and mineralization are in equilibrium). Unlike most elements, carbon is not originally present in the soil. It is taken up from the atmosphere as $\mathrm{CO}_{2}$ and transported to the soil through photosynthesis followed by mineralization of organic matter (or root respiration).

When the mineralization is incomplete, organic acids are formed. $\mathrm{CO}_{2}$ and organic acids are weak acids able to dissociate protons as a function of $\mathrm{pH} . \mathrm{CO}_{2}$ is especially important in calcareous soils with a high $\mathrm{pH}$, whereas organic acids can be important in non-calcareous soils with a low $\mathrm{pH}$ (podzolic soils). The acid production can be quantified by balancing the input of bicarbonate and/or organic anions versus the output (on the assumption that a net production of these anions implies the net production of an equivalent amount of $\mathrm{H}^{+}$).

In soils reduced periodically, the successive reduction and oxidation of iron or sulphur provides an additional source of protons (Brinkman, 1970; van Breemen, 1975). Particularly in the case of sulphur this process can lead to strongly acidified soils, known as acid sulphate soils. However, this is only of regional importance.

Land use. Here, 'land use' refers to the removal of vegetation. This activity disrupts the element cycles and the repercussions are as follows.

- A 'cation surplus', i.e. a surplus of cations over anions, is continuously removed from the soil because of biomass accumulation (uptake exceeds mineralization). In 
this case, nitrogen does not play a role in soil acidification because, like carbon, it is not originally present in the soil. In unfertilized soils, the nitrogen accumulated in biomass (organic matter, vegetation) stems from atmospheric nitrogen $\left(\mathrm{N}_{2}, \mathrm{NO}_{\mathrm{x}}\right.$, $\mathrm{NH}_{3}$ ) and neither this transfer nor the internal transformation of nitrogen from soil organic matter to the vegetation leads to the production or consumption of $\mathrm{H}^{+}$. The net effect of mineralization and uptake is zero for both $\mathrm{NH}_{4}^{+}$and $\mathrm{NO}_{3}^{-}$. Consequently, the 'cation surplus' includes all ions except $\mathrm{NH}_{4}^{+}$and $\mathrm{NO}_{3}^{-}$. Therefore, calculations of the acid production resulting from biomass accumulation, based on a certain $\mathrm{NH}_{4}^{+} / \mathrm{NO}_{3}^{-}$ratio during uptake (Ulrich, 1980; Nilsson, 1983) are wrong. The uptake of a 'cation surplus' causes soil acidification because it decreases the soil's capacity to neutralize acids. The acidification rate can be quantified by measuring the growth rates and chemical composition of the vegetation.

- Mineralization exceeds uptake for a period after the removal of vegetation. This can boost proton production considerably because the quantity of mineralized anions, such as $\mathrm{NO}_{3}^{-}$and $\mathrm{SO}_{4}^{2-}$ (accompanied by $\mathrm{H}^{+}$production) generally exceeds the quantity of mineralized cations (accompanied by $\mathrm{H}^{+}$consumption). The acid production mainly depends upon the nitrification rate. In general, nitrification is rapid, even in acid forest soils (Likens et al., 1969; van Breemen et al., 1984). In this situation, nitrogen plays a dominant role in the acid production. However, the effect is only temporary, because the regrowth of vegetation is generally fast: consequently it is of minor importance in forest soils and of major importance in agricultural soils. The acidification rate can be estimated by balancing input versus output for nitrogen $\left(\mathrm{NH}_{4}^{+}, \mathrm{NO}_{3}^{-}\right)$, sulphate, and cations in the humus layer.

Acid rain. Atmospheric deposition of acidic substances such as $\mathrm{SO}_{2}, \mathrm{NO}_{\mathrm{x}}$ and $\mathrm{NH}_{3}$ ('acid rain') manifests itself in soil by the production of strong acids (sulphuric acid, nitric acid). The potential acidification rate strongly depends on the interception surface and area for dry deposition. Consequently, the acidification rate is generally high in forests. It can be estimated by adding the amount of $\mathrm{NH}_{4}^{+}$in canopy throughfall to the amount of $\mathrm{H}^{+}$in precipitation. The amount of $\mathrm{NH}_{4}^{+}$represents the potential acid production because the $\mathrm{NH}_{4}^{+}$has collected protons from $\mathrm{SO}_{2}$ and $\mathrm{NO}_{x}$ and releases protons upon oxidation to $\mathrm{NO}_{3}^{-}$.

The actual acidification rate caused by acid rain is always lower, because of uptake and/or reduction of nitrate (and sulphate). It can be estimated by balancing input versus output for $\mathrm{H}^{+}, \mathrm{NH}_{4}^{+}$and $\mathrm{NO}_{3}^{-}$(van Breemen et al., 1984).

\section{References}

Breemen, N. van, 1975. Acidification and deacidification of coastal plain soils as a result of periodic flooding. Soil Science Society of America Proceedings 39: 1153-1157.

Breemen, N. van, C. T. Driscoll \& J. Mulder, 1984. The role of acidic deposition and internal proton sources in acidification of soils and water. Nature 307: 599-604.

Breeuwsma, A. \& W. de Vries, 1984. The relative importance of natural $\mathbf{H}^{+}$production in soil acidification. Netherlands Journal of Agricultural Science 32: 161-163.

Brinkman, R., 1970. Ferrolysis, a hydromorphic soil-forming process. Geoderma 3: 199-206.

Likens, G. E., F. H. Bormann \& and N. M. Johnson, 1969. Nitrification: importance to nutrient losses from a cutover forested ecosystem. Science 163: 1205-1206. 
Nilsson, S. I., 1983. Effects on soil chemistry as a consequence of proton input. In: B. Ulrich \& J. Pankrath (Eds.), Effects of air pollutants in forest ecosystems, pp. 105-111. D. Reidel, Dordrecht, Netherlands.

Ulrich, B., 1980. Production and consumption of hydrogen ions in the ecosphere. In: T. C. Hutchinson \& M. Havas (Eds.), Effects of acid precipitation on terrestrial ecosystems, pp. 255-282. Plenum Press, New York.

Ulrich, B., 1983. A concept of forest ecosystem stability and of acid deposition as driving force for destabilization. In: B. Ulrich \& J. Pankrath (Eds.), Effects of air pollutants in forest ecosystems, pp. 1-29. D. Reidel, Dordrecht, Netherlands.

This synopsis is based on a report entitled 'Gevolgen van de zure regen voor de bodem. 1. Oorzaken van bodemverzuring', Soil Survey Institute, Wageningen, 1984. 60 pp., 7 figs., I table, 51 refs. Dutch.

Available as paper copy (order R014P, $f 10$ including postage) or microfiche (order R014M, f 12.50 including postage) at: NARD, clo Pudoc, P.O. Box 4, 6700 AA Wageningen, Netherlands (telex 45015 blhwg $\mathrm{nl}$ ).

\section{The relative importance of natural production of $\mathrm{H}^{+}$in soil acidification}

A. Breeuwsma and W. de Vries (Soil Survey Institute, Marijkeweg 11, 6709 PE Wageningen, Netherlands)

Accepted: 7 June 1984

Abstract. Soil acidification resulting from natural causes is quantified and compared with literature data on soil acidification induced by man via land use and acid rain.

Key-words: soil acidification, natural, anthropogenic, input-output balance, calcareous soils, podzolic soils, acid rain.

Introduction. Acid rain's contribution to soil acidification is controversial. Some authors state that acid rain is a major source of protons (Ulrich, 1983; Ulrich \& Matzner, 1983) whereas others believe soil acidification mainly results from natural causes and land use (Rosenquist et al., 1980; Krug \& Frink, 1983). This dissension arises partly because some authors have only considered parts of the element cycles relevant in soil acidification. In this paper the different acidification sources accounting for all the processes involved are compared quantitatively.

Natural soil acidification. Natural soil acidification mainly results from the dissocia- 